\title{
Diagnosis of Left Ventricular Diastolic Dysfunction Using Cardiac Magnetic Resonance Imaging: Comparison of Volume-Time Curves Derived from Long- and Short-Axis Cine Steady-State Free Precession Datasets
}

\author{
Diagnose der linksventrikulären diastolischen Dysfunktion \\ in der kardialen Magnetresonanztomografie: Vergleich der \\ aus Lang- und Kurzachsen-CINE-SSFP-Sequenzen abgeleiteten \\ Volumen-Zeit-Kurven
}

Authors

Lars-Arne Schaafs ${ }^{1}$, Sebastian Wyschkon ${ }^{1}$, Matthias Elgeti ${ }^{2}$, Sebastian Niko Nagel ${ }^{1}$, Fabian Knebel ${ }^{3}$, Ingo G. Steffen ${ }^{1}$, Marcus R. Makowski ${ }^{1}$, Bernd Hamm¹, Thomas Elgeti¹, 4

Affiliations

1 Department of Radiology, Charité-Universitätsmedizin Berlin, Germany

2 Jules-Eye-Stein-Institute, University of California Los Angeles, United States

3 Department of Cardiology, Charité-Universitätsmedizin Berlin, Germany

4 Department of Nuclear Medicine, CharitéUniversitätsmedizin Berlin, Germany

Key words

cardiac function, magnetic resonance imaging, diastolic

dysfunction, long axis, short axis

received 11.04.2019

accepted 16.01.2020

Bibliography

DOI https://doi.org/10.1055/a-1108-1892

Published online: 27.2 .2020

Fortschr Röntgenstr 2020; 192: 764-775

(c) Georg Thieme Verlag KG, Stuttgart · New York

ISSN 1438-9029

Correspondence

Dr. Sebastian Wyschkon

Department of Radiology, Charité-Universitätsmedizin Berlin, 12203 Berlin, Germany

Tel.: ++49/30/450527792

sebastian.wyschkon@charite.de

\section{ZUSAMMENFASSUNG}

Ziel Vergleich der diagnostischen Genauigkeit von diastolischen Funktionsparametern in der kardialen MRT, die mittels Langachsen (LAX)-Planimetrie bzw. Kurzachsen (SAX) -Volumetrie an Patienten mit diastolischer Dysfunktion erhoben wurden.
Material und Methoden Cine-steady-state-free-precession (SSFP)-Datensätze von 15 gesunden Teilnehmern (8 junge Teilnehmer, 7 Teilnehmer mittleren Alters) sowie 25 Patienten mit echokardiografisch gesicherter diastolischer Dysfunktion (9 mild, 9 moderat und 7 schwer) wurden retrospektiv ausgewertet. Volumen-Zeit-Kurven zur Bewertung der linksventrikulären Funktion wurden nach manuellem Einzeichnen der Endo- bzw. Epikardkontur auf SAX- und LAX-Datensätzen berechnet. Die für jeden Datensatz benötigte Zeit wurde gemessen. Im Anschluss wurden enddiastolisches (EDV) und endsystolisches Volumen (ESV), Ejektionsfraktion (EF), myokardiale Masse (MM), „time-to-peak-fillin-rate“ (TPFR), normalisierte „peak-filling-rate“ (nPFR) und E/A-Verhältnis (E/A) für den linken Ventrikel bestimmt. Unterschiede der Messergebnisse wurden mittels Wilcoxon-Vorzeichen-RangTest geprüft. Die Reliabilität zwischen den Auswertern und zwischen beiden Methoden wurde mittels Intra-KlassenKorrelation gemessen.

Ergebnisse Die höchste diagnostische Genauigkeit wurde mit E/A (Diagnose einer milden diastolischen Dysfunktion) und nPFR (Diagnose einer diastolischen Dysfunktion unabhängig vom Stadium), jeweils generiert aus LAX-Datensätzen, erreicht (E/A: Fläche unter der Kurve =0,97, 68 \% Sensitivität und $100 \%$ Spezifität; nPFR: Fläche unter der Kurve $=0,84$, $84 \%$ Sensitivität und $80 \%$ Spezifität). Die diastolischen Funktionsparameter wiesen im Vergleich eine moderate bis gute Intra-Klassen-Korrelation zwischen beiden Methoden auf. Die mittlere Differenz für EDV, ESV, EF und MM betrug 5,3 ml, $1,9 \mathrm{ml}, 3,5 \%$ beziehungsweise $11 \mathrm{~g}(\mathrm{p}<0,001)$. Die für die Erstellung von Volumen-Zeit-Kurven benötigte Zeit war signifikant kürzer bei der Verwendung von LAX-Datensätzen (Median 14:45 min, Interquartilsabstand 14:15-15:53 min versus median 29:25 min, Interquartilsabstand 28:1232:22 min; $p=0,001)$. Die Reliabilität zwischen beiden Auswertern war gut bis exzellent. 
Schlussfolgerung Die Planimetrie des linken Ventrikels auf Langachsen ergab diastolische Funktionsparameter mit einer hohen diagnostischen Genauigkeit und kann im Vergleich zur Volumetrie in deutlich kürzerer Zeit durchgeführt werden. Diese Erkenntnisse könnten den Einsatz der MRT zur Routinediagnostik der diastolischen Dysfunktion ermöglichen.

\section{Kernaussagen:}

- Mittels Langachsen-Planimetrie berechnete diastolische Funktionsparameter weisen eine hohe diagnostische Aussagekraft auf.

- Die Erstellung von Volumen-Zeit-Kurven durch Auswertung von Langachsen-Datensätzen benötigt deutlich weniger Zeit.

- Diese Zeitersparnis könnte den Einsatz der MRT zur Routinediagnostik der diastolischen Dysfunktion ermöglichen.

\section{ABSTRACT}

Purpose To evaluate the diagnostic performance of diastolic function parameters derived from long-axis (LAX) planimetry compared with short-axis (SAX) volumetry in cardiac magnetic resonance imaging.

Materials and Methods Cine steady-state free precession (SSFP) datasets of 15 healthy participants (8 young and 7 middle aged) and 25 patients with echocardiographically proven diastolic dysfunction ( 9 mild, 9 moderate, and 7 severe) were retrospectively included. Volume-time curves for assessing left ventricular (LV) function were obtained by manually contouring the LV endocardial borders in SAX and LAX datasets. The time needed for contouring was recorded for each dataset. The following LV parameters were determined: end-diastolic volume (EDV), end-systolic volume (ESV), ejection fraction (EF), myocardial mass (MM), time to peak filling rate (TPFR), normalized peak filling rate (nPFR), and the ratio of early to late peak filling rate (E/A ratio). A Wilcoxon signedrank test was used to compare subgroups based on age and severity of diastolic dysfunction for statistical differences. In- traclass correlation coefficients were used to assess intermethod and interobserver reliability.

Results Accuracy for the diagnosis of diastolic dysfunction was highest for E/A (mild diastolic dysfunction) and nPFR (any stage of diastolic dysfunction) derived from LAX datasets (E/A: area under the curve $(A U C)=0.97$, sensitivity of $68 \%$ and specificity of $100 \%$; nPFR: AUC $=0.84$, sensitivity of $84 \%$ and specificity of $80 \%$ ). Diastolic parameters showed a moderate to good intraclass correlation between both methods. The mean differences in EDV, ESV, EF, and MM were $5.3 \mathrm{ml}$, $1.9 \mathrm{ml}, 3.5 \%$, and $11 \mathrm{~g}$, respectively (each $\mathrm{p}<0.001$ ). Significantly less time was needed to derive volume-time curves from LAX images (median 14:45 min, interquartile range 14:15-15:53 min versus median 29:25 min, interquartile range 28:12-32:22 $\mathrm{min} ; \mathrm{p}=0.001$ ). The interobserver reliability was generally good to excellent.

Conclusion Diastolic function parameters derived from left ventricular LAX planimetry have high diagnostic performance and can be obtained in significantly less time compared with SAX volumetry. These findings may pave the way for routine use of LAX planimetry in the clinical diagnosis of diastolic dysfunction.

\section{Key points:}

- Diastolic function parameters derived from long-axis datasets have high diagnostic performance.

- Generation of volume-time curves using long-axis datasets requires significantly less time.

- This time savings may allow use of cardiac MRI for the diagnosis of diastolic dysfunction in the clinical routine.

\section{Citation Format}

- Schaafs LA, Wyschkon S, Elgeti M et al. Diagnosis of Left Ventricular Diastolic Dysfunction Using Cardiac Magnetic Resonance Imaging: Comparison of Volume-Time Curves Derived from Long- and Short-Axis Cine Steady-State Free Precession Datasets. Fortschr Röntgenstr 2020; 192: 764775

\section{Purpose}

Cardiac magnetic resonance imaging (CMR) is considered the gold standard for the evaluation of cardiac function and volume [1, 2].

Assessment of cardiac function and kinetics is routinely performed on long-axis (LAX) and short-axis (SAX) views, which are an integral part of every cardiac imaging examination [3]. As an important parameter, left ventricular volume is most reliably determined on SAX images using Simpson's modified method of slice summation [2]. The segmentation of end-diastolic and endsystolic phases is a well-established method for measuring left ventricular volume and function parameters such as left ventricular ejection fraction (EF) [3].

However, evaluation of diastolic function requires volume-time curves. These may be obtained by segmentation of SAX or by assessing the transmitral and pulmonary vein flow profile using phase- contrast imaging [4-6]. The latter requires careful planning and relies on relatively long breath hold periods, which hampers the widespread clinical implementation of this imaging approach. SAX cine steady-state free precession (SSFP) images are, on the other hand, acquired by default, but generation of volume-time curves relies on assessment of all images across the cardiac cycle. Although substantial progress in semi-automatic segmentation has been made over the last decades, current practice for cine-analysis still comprises substantial input in manual contour tracing or starting and controlling semiautomatic evaluation programs [7-9]. This procedure can become very time-consuming, if manual assessment of the LV endocardial contour in all SAX timeframes is required. This might limit its use in the clinical routine [6]. Although CMR is the reference standard for the evaluation of global cardiac function and kinetics, its use for routine clinical assessment of diastolic function is still in its infancy for the reasons outlined above. 
Interest in diastolic dysfunction and its role in developing heart failure is steadily growing [10-12]. Left ventricular diastolic dysfunction has an estimated prevalence ranging from $22-27 \%$ in a general population and accounts for up to $47 \%$ of patients with heart failure [13-15]. Although echocardiography is the standard of reference for diagnosing diastolic dysfunction in the clinical routine, it appears desirable to have a fast, less time-consuming method for the evaluation of diastolic dysfunction based on CMR images [16]. As studies have confirmed that atrial and ventricular volumes may be obtained reliably using the biplanar area-length method, generating volume-time curves from LAX images would significantly reduce the number of images to be assessed and the associated time expenditure $[17,18]$.

The aim of this retrospective analysis was therefore to investigate whether diastolic function parameters derived from volumetime curves generated from LAX planimetry have similar diagnostic accuracy as using SAX volumetry to determine these parameters.

\section{Materials and Methods}

\section{Study population}

Healthy participants and patients with different stages of left ventricular diastolic dysfunction were included in this retrospective study following approval by the institutional review board (IRB application ID: EA4/040/16). Healthy participants were divided into two age groups: 1 ) age $18-40$ years and 2 ) age $>40$ years. Standard echocardiography served as the standard of reference for diagnosis and grading of diastolic dysfunction. Patients were divided into three subgroups based on echocardiographic grading (i. e., mild, moderate, and severe). Written informed consent was obtained from all participants. This study conforms to the Declaration of Helsinki.

\section{Echocardiography}

Conventional 2 D pulsed-wave Doppler and pulsed-wave tissue Doppler examinations were performed with a phased-array transducer (M4S Vivid 7 Dimension; GE Vingmed, Horton, Norway) using standard parasternal and apical acoustic windows according to the guidelines of the American Society of Echocardiography [19]. Patients were examined in the left lateral decubitus position. Diastolic function was classified applying the criteria of Nagueh et al. [16, 20]. Specifically, mild diastolic dysfunction was considered if patients showed a mitral early/late diastolic ratio (E/A) ratio of less than 0.8 , and a mitral annular velocity ratio (E/e') of less than 8. Diastolic dysfunction was graded moderate, if patients showed an E/A ratio of $0.5-1.5$, E/e' ratio between 9-12, and $e^{\prime}$ of less than $8 \mathrm{~cm} / \mathrm{s}$. Patients with severe diastolic dysfunction showed an E/A ratio greater than 2 and an E/e' greater than 13. Examinations were performed by a single cardiologist $\left({ }^{* *}=\mathrm{FK}\right)$ with over 10 years of experience in echocardiography.

\section{Cardiac magnetic resonance}

CMR was performed at 1.5 T (Avanto and Aera, Siemens Healthineers, Erlangen, Germany). After piloting, double-angulated long cardiac axes and a stack of left ventricular short-axis views were obtained. This was followed by acquisition of retrospectively gated $2 \mathrm{D}$ steady-state free precession (SSFP) pulse sequences in double-angulated long-axis and contiguous short-axis slices from the level of the mitral valve annulus to the left ventricular apex. The scan parameters were as follows: repetition time: $3.5 \mathrm{~ms}$; echo time: $1.6 \mathrm{~ms}$; flip angle: $60^{\circ}$; in-plane spatial resolution: $1.4 \times 1.9 \mathrm{~mm}$; SAX: $8 \mathrm{~mm}$ slice thickness and $2 \mathrm{~mm}$ interslice gap 2; LAX: $5 \mathrm{~mm}$ slice thickness. The reconstructed temporal resolution was 35 to $44 \mathrm{~ms}$, comparable to imaging protocols reported in the literature $[21,22]$.

\section{Quantitative analysis of cardiac function}

For calculation of cardiac function, segmentation of acquired LAX and SAX images was performed by manually contouring the endocardial border across all time points using the commercially available cvi42 ${ }^{\circledR}$ software (version 5.3, Circle Cardiovascular Imaging, Calgary, Canada). Segmentation of LAX images was performed using the biplanar area-length approach whereas SAX images were segmented using the three-dimensional modified slice summation method [17]. The papillary muscles were included in the left ventricular cavity, as suggested in the current literature [2]. Additionally, the epicardial contour was delineated on end-diastolic slices to calculate left ventricular myocardial mass ( $\triangleright$ Fig. 1). The resulting datasets were further analyzed using MATLAB software (MathWorks, Inc, Natick, Massachusetts) to obtain smoothed volume-time curves as described previously [23]. With this approach, volume-time curves were sampled at 1-ms intervals to calculate the first derivative ( $\triangleright$ Fig. 2 ). For quantitative comparison of SAX and LAX analysis the following parameters were determined: end-diastolic volume (EDV), end-systolic volume (ESV), ejection fraction (EF), and left ventricular myocardial mass (MM). For evaluation of diastolic function, we derived the time to peak filling rate (TPFR) and ratio of early to late peak filling rates $(E / A)$ from the first derivative. An exemplary evaluation is shown in $>$ Fig. 3. Lastly, the peak filling rate was normalized to stroke volume (normalized peak filling rate (nPFR)) [5].

\section{Statistical analysis}

After testing with Shapiro-Wilk tests and histograms, a non-parametric distribution of metric data was assumed. A Wilcoxon signed-rank test was used to test for differences between the two approaches. The $95 \%$ limits of agreement were calculated for comparison of parameters derived from SAX and LAX using the method of Bland and Altman. Intraclass correlation coefficients (ICC, two-way random effects, absolute agreement; ICC $(2,1))$ were calculated to assess the agreement between the SAX and LAX method as well as the agreement between the readers. Therefore, five randomly chosen datasets were re-evaluated six months after the first evaluation by the initial reader $\left({ }^{*}=\mathrm{SW}\right.$, six years of experience in CMR) and by a second reader $(* *=T E$, more than 10 years of experience in CMR).

Receiver operating characteristic (ROC) analysis was performed to test the diagnostic performance of LAX planimetry and SAX volumetry using echocardiography as the standard of reference for the diagnosis of diastolic dysfunction. The best cut- 

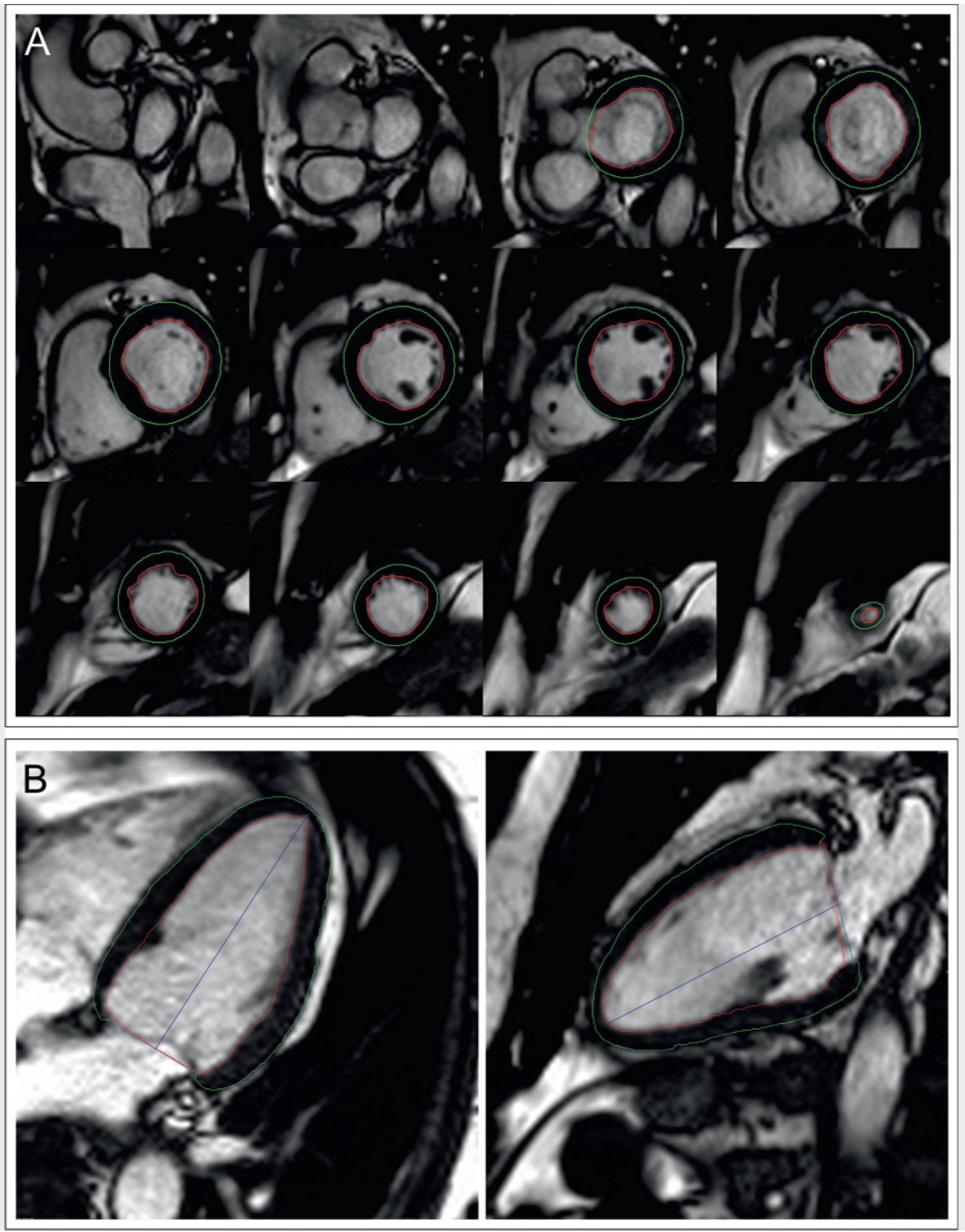

- Fig. 1 Example of left ventricular contour analysis during the end-diastolic phase in the short axis (A: top from base/mitral valve to apex) and long axis (B: bottom, four-chamber view on the left and two-chamber view on the right). Endocardial contour outlined in red, epicardial contour in green.

- Abb. 1 Beispiel einer linksventrikulären Konturanalyse während der enddiastolischen Phase in der Kurzachse (A, oben, von der Herzbasis/ Mitralklappe bis zum Apex) und in der Längsachse (B, unten, 4-Kammeransicht links und 2-Kammeransicht rechts). Die endokardiale Kontur ist rot umrandet, die epikardiale Kontur grün.

off values for E/A, TPFR, and nPFR were determined using the Youden index [24]. Since diastolic function parameters vary with the severity of dysfunction, for $\mathrm{E} / \mathrm{A}$, healthy volunteers were compared only to the group of patients with mild diastolic dysfunction. As suggested in previous studies, healthy volunteers were compared to all patients regarding TPFR and nPFR [5, 25]. Descriptive statistics are given as median and interquartile range (IQR) unless stated otherwise. A p-value $<0.05$ was considered to indicate statis- 


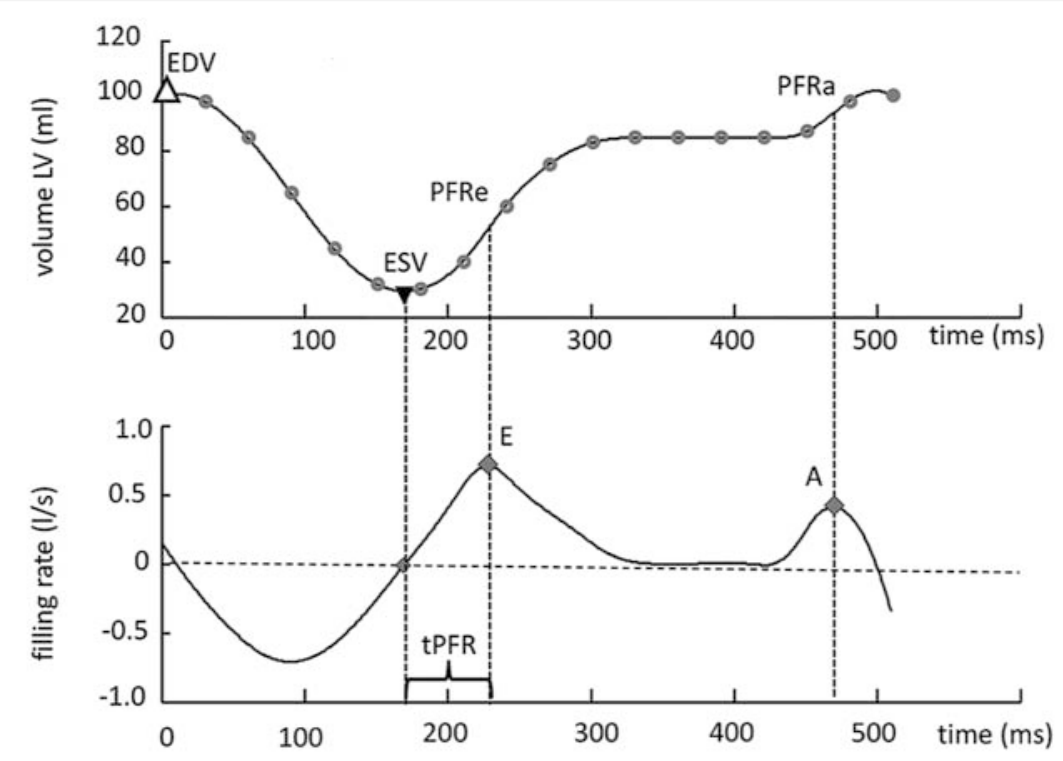

- Fig. 2 Example of a left ventricular volume-time curve (top) and its first derivative representing the filling rate (bottom). End-diastolic and endsystolic volumes are tagged with open and filled triangles, respectively. The filling rate curve reaches zero in end-systole and reaches its first maximum (E) at peak filling rate. Time to peak filling rate (TPFR) is the interval between zero crossing at end-systole and first maximum of the filling rate curve. The second maximum of the filling rate curve marks maximum atrial filling (A). E/A is calculated as the ratio of PFRE to PFRA.

- Abb.2 Beispiel einer linksventrikulären Volumen-Zeit-Kurve (oben) und ihrer ersten Derivation, die die Füllrate darstellt (unten). Enddiastolische und endsystolische Volumina werden als leere bzw. gefüllte Dreiecke dargestellt. Die Kurve der Füllrate erreicht in der Endsystole 0 und erreicht bei maximaler Füllrate ihr erstes Maximum (E). Die „time to peak rate“ (TPFR) ist definiert als das Intervall zwischen dem 0-Durchgang während der Endsystole und dem ersten Maximum der Füllratenkurve. Das zweite Maximum der Füllratenkurve stellt die maximale Vorhoffüllung (A) dar. E/A wird berechnet als das Verhältnis von PFRE zu PFRA.

tically significant differences. Statistical analysis was performed using R 3.1.3 (The R Foundation for Statistical Computing, Vienna, Austria).

\section{Results}

\section{Descriptive statistics}

15 healthy participants were included in this study: 8 young participants (4 female) with a median age of 27.5 (IQR 8) years and 7 middle-aged participants ( 5 female) with a median age of 59 (IQR 8) years. Furthermore, 25 participants with echocardiographically proven diastolic dysfunction were included. 9 participants suffered from mild diastolic dysfunction, another 9 participants had moderate diastolic dysfunction, and 7 participants with severe diastolic dysfunction were included. A summary of descriptive statistics (physical parameters, echocardiographically measured VE/VA and E/E' and global systolic parameters derived from (MR) is given in Table 1.

\section{Agreement of CMR methods}

A summary of comparative statistics is given in $>$ Table 2. Comparison of the two approaches yielded significantly higher values for EDV (mean difference $5.3 \mathrm{ml}, \mathrm{p}=0.008$ ), EF (mean difference $3.5 \%, p=0.004$ ) and MM derived from LAX datasets (mean differ- ence $=11 \mathrm{~g}, \mathrm{p}=0.001)$. There were no statistically significant differences between $L A X$ and SAX evaluation regarding ESV $(p=0.162)$, TPFR $(p=0.868), n P F R(p=0.06)$, and $E / A(p=0.242)$. Both approaches had narrow $95 \%$ limits of agreement (LOA) in Bland-Altman analysis approximately below $5 \%$ for EDV, ESV, EF and TPFR. For MM, E/A and nPFR the LOA ranged up to $9 \%, 12 \%$, and $13 \%$, respectively.

A comparison of diastolic parameters derived from LAX and SAX datasets is given in $>$ Table 3.

\section{Evaluation time}

The time needed to derive volume-time curves from SAX volumetry was significantly longer with a median of 29:25 min (interquartile range: $28: 12-32: 22 \mathrm{~min}$ ) in comparison to LAX planimetry with a median of $14: 45 \mathrm{~min}$ (interquartile range: 14:15$15: 53 \min )(p=0.001)$.

\section{Interobserver agreement}

The interobserver variability showed a smaller LOA than the comparison of both methods, except for TPFR SAX. The corresponding interobserver agreement showed good to excellent values with ICCs ranging between 0.78 and 0.99 . 


\section{A: short axis}
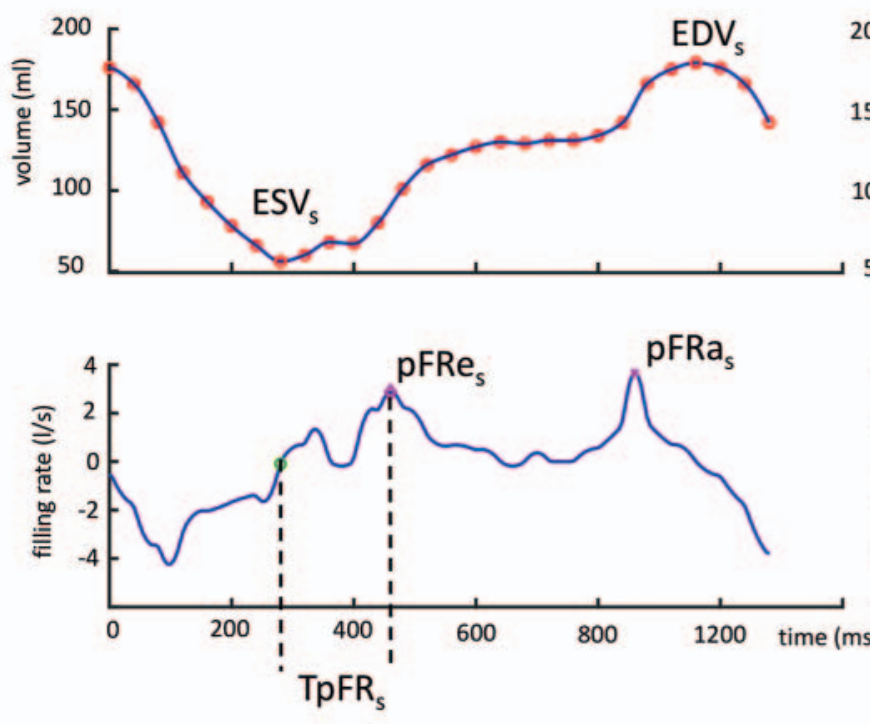

\section{B: long axis}
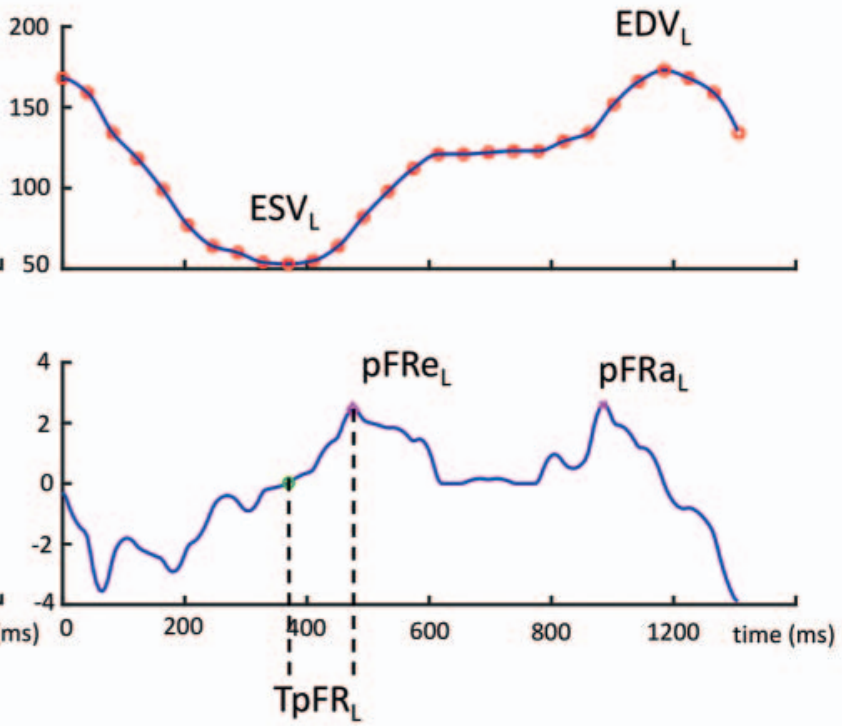

- Fig. 3 Example of an analysis in a patient with moderate diastolic dysfunction (grade 2). The volume-time curve derived from short-axis evaluation is shown on the left side $\mathbf{A}$, and the curve derived from long-axis evaluation on the right side $\mathbf{B}$. Global and systolic cardiac parameters were EDV 171/168 ml, ESV 55/53 ml, EF 68/69\%, respectively. Diastolic parameters were TPFR 140/150 ms, nPFR 2.48/1.98 ml/s and E/A 0.76/0.67, respectively.

- Abb. 3 Beispiel einer Auswertung bei einem Patienten mit moderater diastolischer Dysfunktion (Grad 2). Auf der linken Seite A ist die aus der Kurzachsen-Auswertung abgeleitete Volumen-Zeit-Kurve dargestellt, auf der rechten Seite B die aus der Langachsen-Auswertung abgeleitete Kurve. Globale und systolische Herzparameter: EDV 171/168 ml, ESV 55/53 ml, EF 68/69\%. Diastolische Parameter: TPFR 140/150 ms, nPFR 2,48/1,98 ml/s und E/A 0,76/0,67.

- Table 1 Descriptive statistics subdivided into five subgroups. All values are given as median (and interquartile range). The systolic function parameters were obtained by CMR (modified method of slice summation by Simpson).

- Tab. 1 Deskriptive Statistiken unterteilt in 5 Subgruppen. Alle Werte werden als Median (und Interquartilsabstand) angegeben. Die systolischen Funktionsparameter wurden mit der kardialen MRT ermittelt (Kurzachsenvolumetrie).

\begin{tabular}{|c|c|c|c|c|c|}
\hline & young healthy & $\begin{array}{l}\text { middle aged } \\
\text { healthy }\end{array}$ & $\begin{array}{l}\text { mild diastolic } \\
\text { dysfunction }\end{array}$ & $\begin{array}{l}\text { moderate dias- } \\
\text { tolic dysfunction }\end{array}$ & $\begin{array}{l}\text { severe diastolic } \\
\text { dysfunction }\end{array}$ \\
\hline$n=$ & 8 (4 female) & 7 (5 female) & 9 (4 female) & 9 (2 female) & 7 (4 female) \\
\hline \multicolumn{6}{|c|}{ physical parameters } \\
\hline age (years) & $27.5(8)$ & $59.0(8)$ & $63.0(19)$ & $66.0(15)$ & $64.0(15)$ \\
\hline height (cm) & $179.5(16)$ & $171.5(10)$ & $176.0(18)$ & $175.0(16)$ & $168.0(16)$ \\
\hline weight (kg) & $72.0(21)$ & $60.5(12)$ & $78.0(37)$ & $83.0(18)$ & $80.0(16)$ \\
\hline BMI $\left(\mathrm{kg} / \mathrm{m}^{2}\right)$ & $23.5(6)$ & $20.0(4)$ & $28.0(9)$ & $28.0(6)$ & $27.0(6)$ \\
\hline \multicolumn{6}{|c|}{ echocardiography (diastolic parameter) } \\
\hline $\mathrm{E} / \mathrm{A}$ & $1.15(0.3)$ & $1.0(0.2)$ & $0.7(0.1)$ & $0.8(0.3)$ & $0.8(1.1)$ \\
\hline $\mathrm{E} / \mathrm{e}^{\prime}$ & $4.8(1.7)$ & $6.4(1.4)$ & $8.4(0.8)$ & $10.6(2.1)$ & $16.6(5.8)$ \\
\hline \multicolumn{6}{|c|}{ CMR (global systolic parameter) } \\
\hline EDV (ml) & $153.0(33)$ & $123.5(33)$ & $100.0(40)$ & $135.0(79)$ & $172.0(86)$ \\
\hline $\mathrm{ESV}(\mathrm{ml})$ & $54.9 \pm 4.8$ & $43.7 \pm 3.9$ & $41.2 \pm 5.3$ & $58.1 \pm 11.6$ & $71 \pm 20.4$ \\
\hline SV (ml) & $101.5(20)$ & 75 (19) & $65.0(26)$ & $83.0(49)$ & $73.0(62)$ \\
\hline $\mathrm{EF}(\%)$ & $65.0(10)$ & $62.0(13)$ & $65.0(13)$ & $64.0(12)$ & $52.0(23)$ \\
\hline
\end{tabular}


- Table 2 Systolic and diastolic function parameters derived from long- (LAX) and short-axis (SAX) datasets $(n=40)$. All values are given as median and interquartile range (IQR). For the purpose of comparison of both methods (middle columns) and readers (right columns), the mean difference (level of significance using Wilcoxon-paired signed rank test), the $95 \%$ level of agreement (LOA) calculated according to the method of Bland and Altman and the intraclass correlation coefficient (ICC) are given.

- Tab. 2 Systolische und diastolische Funktionsparameter, berechnet jeweils aus Lang- (LAX) und Kurzachsendatensätzen $(S A X)(n=40)$. Alle Werte werden als Median und Interquartilsbereich (IQR) angegeben. Zum Vergleich beider Methoden (mittlere Spalten) und beider Bewerter (rechte Spalten) werden die Parameter Mittelwertdifferenz, Grenzen der Übereinstimmung (level of agreement, LOA) auf Bland-Altman-Plots und die Intra-Klassen-Korrelation (intraclass correlation coefficient, ICC) aufgeführt.

\begin{tabular}{|c|c|c|c|c|c|c|}
\hline & mean $\pm S D$ & $\begin{array}{l}\text { median } \\
\text { (IQR) }\end{array}$ & $\begin{array}{l}\text { mean difference } \\
\text { methods, } 95 \% \text { LOA }\end{array}$ & ICC methods & $\begin{array}{l}\text { mean difference } \\
\text { readers, } 95 \% \text { LOA }\end{array}$ & ICC readers \\
\hline EDV SAX (ml) & $139.6 \pm 42.8$ & $133(106.8-159)$ & \multirow[t]{2}{*}{$\begin{array}{l}5.3(p=0.008) \\
-22-32.7\end{array}$} & \multirow[t]{2}{*}{0.94} & $\begin{array}{l}1.0(p=0.581) \\
-4.3-6.3\end{array}$ & 0.99 \\
\hline EDV LAX (ml) & $144.9 \pm 42.2$ & 139 (115.5-159) & & & $\begin{array}{l}1.4(p=0.423) \\
-3.6-6.4\end{array}$ & 0.99 \\
\hline ESV SAX (ml) & $54.1 \pm 29.3$ & $44(38.9-61.2)$ & \multirow[t]{2}{*}{$\begin{array}{l}-1.9(p=0.162) \\
-17.6-13.7\end{array}$} & \multirow[t]{2}{*}{0.96} & $\begin{array}{l}-0.2(p=0.8) \\
-3.8-3.4\end{array}$ & 0.97 \\
\hline ESV LAX (ml) & $52.2 \pm 30$ & $46(32.8-54.5)$ & & & $\begin{array}{l}-1.2(p=0.08) \\
-5.1-2.7\end{array}$ & 0.96 \\
\hline EF SAX (\%) & $62.1 \pm 9.8$ & $64(57-68.3)$ & \multirow[t]{2}{*}{$\begin{array}{l}3.5(p=0.004) \\
-9.8-16.8\end{array}$} & \multirow[t]{2}{*}{0.72} & $\begin{array}{l}0.60(p=0.09) \\
-2.4-3.6\end{array}$ & 0.97 \\
\hline EF LAX (\%) & $65.5 \pm 9.8$ & $68.4(60.2-71.5)$ & & & $\begin{array}{l}1.2(p=0.13) \\
-1.4-3.8\end{array}$ & 0.94 \\
\hline MM SAX (g) & $128.8 \pm 43.4$ & $122.5(91.5-147.5)$ & \multirow[t]{2}{*}{$\begin{array}{l}11(p=0.001) \\
-1.1-23.2\end{array}$} & \multirow[t]{2}{*}{0.96} & $\begin{array}{l}-5.6(p=0.06) \\
-16.5-5.3\end{array}$ & 0.99 \\
\hline MM LAX (g) & $141 \pm 45$ & $136(102.5-161.5)$ & & & $\begin{array}{l}7.4(p=0.06) \\
-0.16-14.9\end{array}$ & 0.98 \\
\hline E/A SAX & $1.88 \pm 1.34$ & $1.43(0.92-2.61)$ & \multirow[t]{2}{*}{$\begin{array}{l}-0.21(p=0.242) \\
-1.94-1.51\end{array}$} & \multirow[t]{2}{*}{0.74} & $\begin{array}{l}0.15(p=0.06) \\
-0.06-0.36\end{array}$ & 0.88 \\
\hline E/A LAX & $1.67 \pm 1.08$ & $1.39(0.91-1.91)$ & & & $\begin{array}{l}0.06(p=0.63) \\
-0.18-0.30\end{array}$ & 0.98 \\
\hline TPFR SAX (ms) & $150.6 \pm 31.5$ & $140(130-165)$ & \multirow[t]{2}{*}{$\begin{array}{l}-2.25(p=0.868) \\
-65.3-60.8\end{array}$} & \multirow[t]{2}{*}{0.55} & $\begin{array}{l}3.0(p=0.78) \\
-40.4-46.4\end{array}$ & 0.21 \\
\hline TPFR LAX (ms) & $148.4 \pm 34.9$ & $142.5(128.8-167.5)$ & & & $\begin{array}{l}2.0(p=0.71) \\
-18.7-22.7\end{array}$ & 0.93 \\
\hline nPFR SAX (ml/s) & $2.99 \pm 1.07$ & $2.80(2.16-3.59)$ & \multirow[t]{2}{*}{$\begin{array}{l}0.40(p=0.06) \\
-2.96-3.75\end{array}$} & \multirow[t]{2}{*}{0.21} & $\begin{array}{l}0.15(p=0.31) \\
-0.27-0.56\end{array}$ & 0.78 \\
\hline nPFR LAX (ml/s) & $3.38 \pm 1.56$ & $3.18(2.55-3.70)$ & & & $\begin{array}{l}-0.36(p=0.06) \\
-0.67-(-0.06)\end{array}$ & 0.82 \\
\hline
\end{tabular}

$E D V=$ end-diastolic volume, $E S V=$ end-systolic volume, $S V=$ stroke volume, $E F=$ ejection fraction, $M M=$ myocardial mass, $E / A=E / A-r a t i o$, TPFR $=$ time to peak filling rate, $\mathrm{nPFR}=$ normalized peak filling rate.

$\mathrm{EDV}=$ enddiastolisches Volumen; $\mathrm{ESV}=$ endsystolisches Volumen; $\mathrm{SV}=$ Schlagvolumen; $\mathrm{EF}$ = Ejektionsfraktion; $\mathrm{MM}$ = myokardiale Masse;

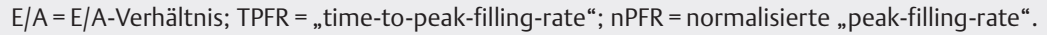

\section{Separation of healthy participants from patients with diastolic dysfunction}

In terms of differentiating healthy participants from participants with any stage of diastolic dysfunction, nPFR showed a higher diagnostic performance when derived from LAX planimetry. Here, the best cut-off was found to be 3.2 with an area under the ROC curve (AUROC) of 0.84 ( $p<0.001$ ), yielding $84 \%$ sensitivity and $80 \%$ specificity. A cut-off of 2.9 was found optimal for SAX datasets (AUROC $=0.75, p=0.049 ; 80 \%$ sensitivity, $67 \%$ specificity). The performance of TPFR was higher when derived from SAX images (AUROC $=0.86, p=0.004 ; 60 \%$ sensitivity, $93 \%$ specificity) rather than from LAX images (AUROC $=0.76, p=0.007,64 \%$ sensitivity, $73 \%$ specificity). The ROC analyses of the different parameters derived from CMR to separate healthy participants from patients with echocardiographically proven diastolic dysfunction is displayed in $>$ Fig. 4. 
- Table 3 Comparison of diastolic parameters derived from long- (LAX) and short-axis (SAX) datasets. All values are given as median and interquartile range (IQR).

- Tab.3 Vergleich diastolischer Funktionsparameter, berechnet jeweils aus Lang- (LAX) und Kurzachsendatensätzen (SAX). Alle Werte werden als Median und Interquartilsbereich (IQR) angegeben.

\begin{tabular}{|c|c|c|c|c|c|}
\hline & $\begin{array}{l}\text { young } \\
n=8\end{array}$ & $\begin{array}{l}\text { middle aged } \\
n=7\end{array}$ & $\begin{array}{l}\text { mild diastolic } \\
\text { dysfunction } \\
n=9\end{array}$ & $\begin{array}{l}\text { moderate diastolic } \\
\text { dysfunction } \\
n=9\end{array}$ & $\begin{array}{l}\text { severe diastolic } \\
\text { dysfunction } \\
n=9\end{array}$ \\
\hline nPFR SAX & $\begin{array}{l}3.2 \pm 0.9 \\
3.3(2.4-3.7)\end{array}$ & $\begin{array}{l}3.9 \pm 1.3 \\
3.5(3.5-4.2)\end{array}$ & $\begin{array}{l}2.8 \pm 1.2 \\
2.2(2.1-2.9)\end{array}$ & $\begin{array}{l}2.7 \pm 0.7 \\
2.5(2.3-3.4)\end{array}$ & $\begin{array}{l}2.6 \pm 1.0 \\
2.7(1.7-3.2)\end{array}$ \\
\hline nPFR LAX & $\begin{array}{l}3.8 \pm 0.8 \\
3.5(3.3-4.1)\end{array}$ & $\begin{array}{l}3.5 \pm 0.5 \\
3.5(3.2-3.8)\end{array}$ & $\begin{array}{l}2.6 \pm 0.7 \\
2.5(2.2-2.9)\end{array}$ & $\begin{array}{l}2.8 \pm 0.9 \\
2.9(3.1-3.2)\end{array}$ & $\begin{array}{l}2.6 \pm 1-0 \\
2.7(1.7-3.2)\end{array}$ \\
\hline E/A SAX & $\begin{array}{l}2.1 \pm 1.3 \\
1.9(1.8-2.4)\end{array}$ & $\begin{array}{l}2.2 \pm 0.9 \\
1.9(1.4-2.9)\end{array}$ & $\begin{array}{l}1.0 \pm 0.3 \\
0.9(0.8-1.2 .)\end{array}$ & $\begin{array}{l}1.2 \pm 0.7 \\
1.1(0.8-1.5)\end{array}$ & $\begin{array}{l}3.3 \pm 1.9 \\
3.6(1.8-4.8)\end{array}$ \\
\hline E/A LAX & $\begin{array}{l}2.2 \pm 0.8 \\
1.9(1.8-2.4)\end{array}$ & $\begin{array}{l}1.7 \pm 0.4 \\
1.7(1.4-1.9)\end{array}$ & $\begin{array}{l}0.9 \pm 0.3 \\
0.9(0.8-1.1)\end{array}$ & $\begin{array}{l}1.1 \pm 0.4 \\
1.0(0.8-1.4)\end{array}$ & $\begin{array}{l}2.7 \pm 1.9 \\
2.9(1.0-4.0)\end{array}$ \\
\hline TPFR SAX & $\begin{array}{l}133.1 \pm 8 \\
135(128.8-136.2)\end{array}$ & $\begin{array}{l}128.6 \pm 14.9 \\
130(122.5-135)\end{array}$ & $\begin{array}{l}163.3 \pm 30.8 \\
160(145-180)\end{array}$ & $\begin{array}{l}173.3 \pm 41.5 \\
190(130-205)\end{array}$ & $\begin{array}{l}147.1 \pm 24 \\
150(137.5-160)\end{array}$ \\
\hline TPFR LAX & $\begin{array}{l}130 \pm 23 \\
137.5(116.2-146.2)\end{array}$ & $\begin{array}{l}127.1 \pm 27.4 \\
125(107.5-135)\end{array}$ & $\begin{array}{l}163.9 \pm 36.6 \\
175(130-180)\end{array}$ & $\begin{array}{l}170 \pm 41.7 \\
150(135-215)\end{array}$ & $\begin{array}{l}142.9 \pm 19.1 \\
145(140-152.5)\end{array}$ \\
\hline
\end{tabular}

\section{Diagnosis of mild diastolic dysfunction}

Determination of E/A from LAX datasets showed a higher diagnostic performance than E/A derived from SAX datasets. For LAX, the best threshold was 1.2, yielding an area under the ROC curve (AUROC) of $0.97(p<0.001)$ with a sensitivity of $68 \%$ and a specificity of $100 \%$. For SAX, the best threshold was found to be 1.25 with an AUROC of $0.89(p<0.001)$, yielding a sensitivity of $60 \%$ and a specificity of $93 \%$. The diagnostic performance of nPFR was also higher when derived from LAX planimetry. Here, the optimal cut-off was $3.2 \mathrm{ml} / \mathrm{ms}$ with an AUROC of $0.87(p=0.003)$, yielding a sensitivity of $89 \%$ and a specificity of $87 \%$. In SAX datasets, the best cut-off for $\mathrm{nPFR}$ was $2.9 \mathrm{ml} / \mathrm{ms}$ ( $A \cup R O C=0.75$, $p=0.049 ; 89 \%$ sensitivity, $67 \%$ specificity). Other than $E / A$ and nPFR, the diagnostic performance of TPFR was higher when obtained using SAX volumetry; the best cut-off was $145 \mathrm{~ms}$ ( $A \cup R O C=0.86, p=0.004 ; 78 \%$ sensitivity, $87 \%$ specificity) versus $165 \mathrm{~ms}$ for LAX datasets (AUROC of $0.77, \mathrm{p}=0.029 ; 67 \%$ sensitivity, $93 \%$ specificity). The ROC analyses for the different CMR-derived diastolic parameters to differentiate mild diastolic dysfunction are given in $>$ Fig. $\mathbf{5}$.

\section{Discussion}

To our knowledge, this study shows for the first time that diastolic function parameters derived using the biplanar area-length method have satisfying diagnostic performance for diagnosis of diastolic dysfunction using CMR. The parameters E/A (for diagnosis of mild diastolic dysfunction) and nPFR (any stage of diastolic dysfunction) showed a superior diagnostic performance and a higher interobserver agreement compared to their counterparts derived from short-axis volumetry.

The diagnostic information obtained with CMR can thus be further enhanced by adding information on diastolic dysfunction, a field routinely covered by echocardiography but of increasing interest, as it is clinically relevant and associated with a poor prognosis [26, 27]. Furthermore, even detection of preclinical diastolic dysfunction might be helpful in risk stratification [28]. However, further clarification is required with regard to the parameters used and their thresholds, especially as automated segmentation software might become available in the clinical routine. Mendoza et al. obtained left ventricular volume-time curves using automated LV segmentation and determined cut-off values to separate healthy participants from different stages of diastolic dysfunction in a total of 115 subjects [5]. For TPFR, Mendoza et al. found the best threshold to separate healthy participants from patients with diastolic dysfunction to be $221 \mathrm{~ms}$. For this cut-off, they found sensitivities of $48 \%$ for grade $1,29 \%$ for grade 2 , and $0 \%$ for grade 3 . The specificity was $83 \%$ for all three grades of diastolic dysfunction. For nPFR, Mendoza et al. reported an optimal threshold of $4.02 / \mathrm{s}$ with a sensitivity of $0 \%$ (grade 1 ), $9 \%$ (grade 2 ) and $67 \%$ (grade 3), while a consistent specificity of $83 \%$ was found for all three grades. While the absolute thresholds obtained in this study differ significantly from our results, the patterns of change in TPFR and nPFR across the different stages of diastolic dysfunction are comparable. This observation suggests that differences in absolute values and diagnostic accuracy appear to be mainly attributable to the use of different approaches for obtaining the volume-time curves. 

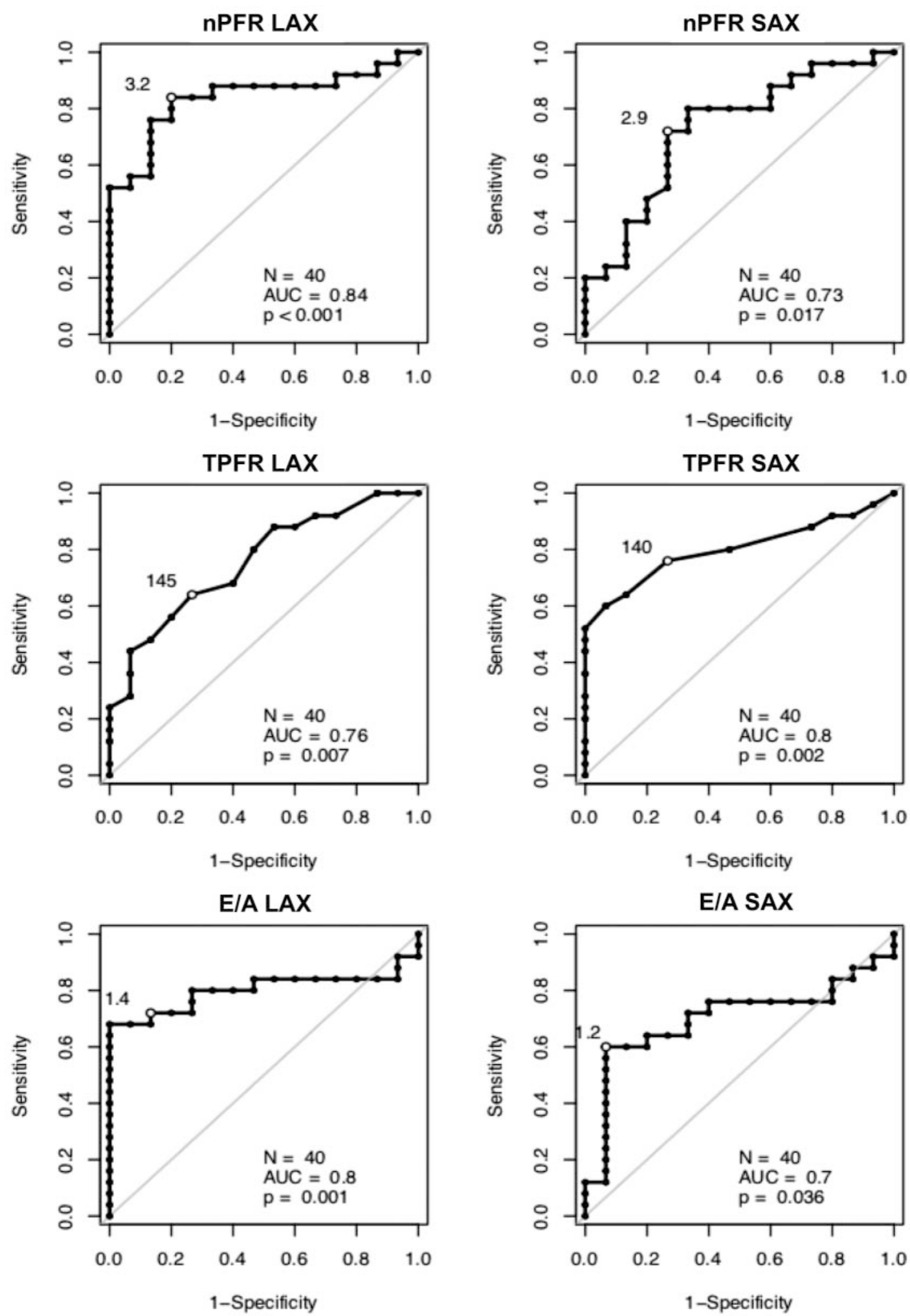

- Fig. 4 ROC analysis for diastolic function parameters nPFR, TPFR, and E/A derived from CMR volume-time curves in LAX (left side) and SAX (right side) evaluation. The best cut-offs to differentiate between diastolic dysfunction and healthy volunteers are displayed in the figure.

- Abb.4 ROC-Analyse für die diastolischen Funktionsparameter nPFR, TPFR und E/A, jeweils erhoben auf Langachsen-Sequenzen (links) und Kurzachsen-Sequenzen (rechts). Die cut-off-Werte zur Differenzierung zwischen Patienten mit diastolischer Dysfunktion und gesunden Teilnehmern sind in der Abbildung angegeben. 

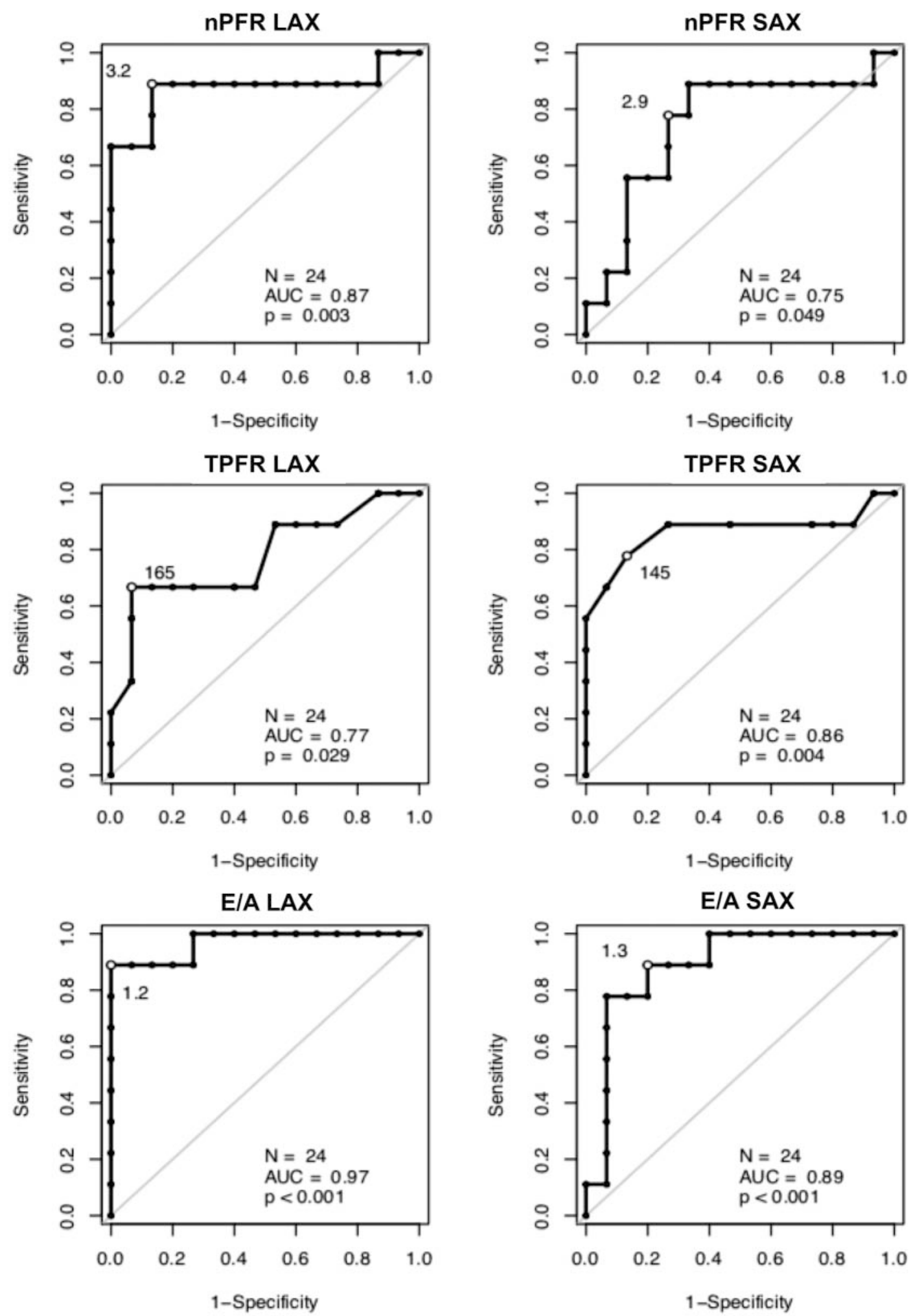

- Fig. 5 ROC analysis for diastolic function parameters nPFR, TPFR, and E/A derived from CMR volume-time curves in LAX (left side) and SAX (right side) evaluation. The best cut-offs to differentiate between mild diastolic dysfunction and healthy volunteers are displayed in the figure.

- Abb.5 ROC-Analyse für die diastolischen Funktionsparameter nPFR, TPFR und E/A, jeweils erhoben auf Langachsen-Sequenzen (links) und Kurzachsen-Sequenzen (rechts). Die cut-off-Werte zur Differenzierung zwischen Patienten mit milder diastolischer Dysfunktion und gesunden Teilnehmern sind in der Abbildung angegeben. 
Effective temporal resolution of the original cine datasets used was 35-44 ms, and a smoothed volume-time curve was derived by postprocessing. This approach is comparable to techniques described in the literature [22]. The approach used in our study includes retrospective gating and 25 time points of the cine-loops. In contrast, Zeidan et al. used prospectively gated cine-loops obtaining only $90 \%$ of the RR interval and 18 time steps, which is less suitable for deriving parameters characterizing the diastolic phase of the cardiac cycle [23]. It is known that a higher temporal resolution of LV kinetics depicts certain features such as the isovolumetric relaxation time more precisely - especially during the diastolic phase of the cardiac cycle [29]. Therefore, further studies should investigate if using a higher temporal resolution might further improve diagnostic use of cine SSFP sequences for the evaluation of diastolic dysfunction.

Different approaches have been tested to overcome the tedious and time-consuming manual segmentation of the endocardial border [30, 31]. However, manual segmentation is still considered the standard of reference [31, 32]. It is known that short-axis volumetry might provide higher values for EDV and EF as modeling is less geometric. Nevertheless, a few large population-based studies did not use EDV and EF derived from $3 \mathrm{D} M \mathrm{MR}$ imaging but rather utilized $2 \mathrm{D}$ planar echocardiography [33]. Therefore, automated segmentation of cine long axes has been developed and investigated recently [32]. Shahzad et al. evaluated a fully automated segmentation pipeline of two long-axis cine views and found high Dice coefficients between 0.85 and 0.97 for systolic parameters and myocardial mass. This approach might also be helpful in assessing diastolic function parameters more rapidly. However, CMR offers various additional techniques as possible future indices for diastolic dysfunction such as LV deformation imaging, phase contrast CMR, and T1 mapping as well as extracellular volume calculation [34].

The following limitations of our study need to be taken into account. First, in our patients and volunteers, global cardiac and systolic functional parameters like EDV, ESV, EF, and MM exhibited significant statistical differences between the two approaches, while the absolute differences where rather minor and the ICC was high to very high. These findings are similar to other CMR studies comparing the assessment of LV function using SAX and LAX datasets, and it should be reconsidered whether a statistically significant difference is actually clinically relevant [17, 35]. Second, we only included a relatively small number of subjects. However, as it is known that diastolic function parameters vary with age, we analyzed two age groups of volunteers (young vs. middle-aged), and we evaluated patients with different stages of echocardiographically proven diastolic dysfunction. Thus, despite the small number of subjects, our study design allows a differentiated interpretation of the diastolic function parameters investigated here. Third, it is known that small deviations in segmentation in the volume curve can be amplified in the derivative [5]. This might explain the relatively large standard deviation of diastolic function parameters, which were derived from the first derivative of the volume-time curve. Lastly, the interreader variability for diastolic parameters based on manual segmentation was slightly worse compared with results reported in the literature for semiautomatic approaches [5]. Our results may in part be attributable to the small number of subjects evaluated for interrater agreement in our study.

\section{Conclusion}

Function parameters for identifying and grading diastolic dysfunction derived from the biplanar area-length method showed high diagnostic performance and can be determined in much less time compared to analysis of short-axis images. These findings may pave the way for use of the biplanar area-length method to assess diastolic function in the clinical routine.

\section{CLINICAL RELEVANCE}

- Deriving left ventricular volume-time curves using the biplanar area-length method is significantly less timeconsuming.

- The resulting diastolic function parameters have high diagnostic accuracy.

- Using the biplanar area-length method may enable CMR to be established for the diagnosis of diastolic dysfunction in the clinical routine.

Conflict of Interest

The authors declare that they have no conflict of interest.

\section{References}

[1] Luetkens ], Petry P, Kuetting D et al. Left and right ventricular strain in the course of acute myocarditis: a cardiovascular magnetic resonance study. RöFo - Fortschritte Auf Dem Gebiet Der Röntgenstrahlen Und Der Bildgebenden Verfahren 2018; 190: 722-732

[2] Petersen SE, Aung N, Sanghvi MM et al. Reference ranges for cardiac structure and function using cardiovascular magnetic resonance (CMR) in Caucasians from the UK Biobank population cohort. Journal of Cardiovascular Magnetic Resonance 2017; 19: 18

[3] Schulz-Menger J, Bluemke DA, Bremerich J et al. Standardized image interpretation and post processing in cardiovascular magnetic resonance: Society for Cardiovascular Magnetic Resonance (SCMR) Board of Trustees Task Force on Standardized Post Processing. Journal of cardiovascular magnetic resonance: official journal of the Society for Cardiovascular Magnetic Resonance 2013; 15: 35

[4] Bollache E, Redheuil A, Clément-Guinaudeau S et al. Automated left ventricular diastolic function evaluation from phase-contrast cardiovascular magnetic resonance and comparison with Doppler echocardiography. Journal of Cardiovascular Magnetic Resonance 2010; 12: 63

[5] Mendoza DD, Codella NC, Wang Y et al. Impact of diastolic dysfunction severity on global left ventricular volumetric filling - assessment by automated segmentation of routine cine cardiovascular magnetic resonance. Journal of Cardiovascular Magnetic Resonance: Official Journal of the Society for Cardiovascular Magnetic Resonance 2010; 12: 46

[6] Caudron J, Fares J, Bauer F et al. Evaluation of Left Ventricular Diastolic Function with Cardiac MR Imaging. RadioGraphics 2011; 31: 239-259

[7] Tao Q, Yan W, Wang Y et al. Deep Learning-based Method for Fully Automatic Quantification of Left Ventricle Function from Cine MR Images: A Multivendor, Multicenter Study. Radiology 2019; 290: 81-88 
[8] Wang Y, Zhang Y, Kao E et al. Fully automatic segmentation of 4D MRI for cardiac functional measurements. Medical Physics 2019; 46: 180-189

[9] Nassenstein K, de Greiff A, Hunold P. MR Evaluation of Left Ventricular Volumes and Function: Threshold-Based 3D Segmentation Versus ShortAxis Planimetry. Investigative Radiology 2009; 44: 635-640

[10] Daud A, Xu D, Revelo MP et al. Microvascular Loss and Diastolic Dysfunction in Severe Symptomatic Cardiac Allograft Vasculopathy. Circulation: Heart Failure 2018; 11: e004759

[11] Toida T, Toida R, Yamashita R et al. Grading of Left Ventricular Diastolic Dysfunction with Preserved Systolic Function by the 2016 American Society of Echocardiography/European Association of Cardiovascular Imaging Recommendations Contributes to Predicting Cardiovascular Events in Hemodialysis Patients. Cardiorenal Medicine 2019; 9: 190-200

[12] Fabiani I, Pugliese N, Carrubba S et al. Interactive role of diastolic dysfunction and ventricular remodeling in asymptomatic subjects at increased risk of heart failure. The International Journal of Cardiovascular Imaging 2019; 35: 1231-1240

[13] Owan TE, Hodge DO, Herges RM et al. Trends in prevalence and outcome of heart failure with preserved ejection fraction. The New England Journal of Medicine 2006; 355: 251-259

[14] Kloch-Badelek M, Kuznetsova T, Sakiewicz W et al. Prevalence of left ventricular diastolic dysfunction in European populations based on cross-validated diagnostic thresholds. Cardiovascular Ultrasound 2012; 10: 10

[15] Kuznetsova T, Herbots L, López B et al. Prevalence of Left Ventricular Diastolic Dysfunction in a General Population. Circulation: Heart Failure 2009; 2: 105-112

[16] Nagueh S, Smiseth O, Appleton C et al. Recommendations for the Evaluation of Left Ventricular Diastolic Function by Echocardiography: An Update from the American Society of Echocardiography and the European Association of Cardiovascular Imaging. Journal of the American Society of Echocardiography 2016; 29: 277-314

[17] Childs H, Ma L, Ma M et al. Comparison of long and short axis quantification of left ventricular volume parameters by cardiovascular magnetic resonance, with ex-vivo validation. Journal of Cardiovascular Magnetic Resonance 2011; 13: 40

[18] Abhayaratna WP, Seward JB, Appleton CP et al. Left Atrial Size Physiologic Determinants and Clinical Applications. Journal of the American College of Cardiology 2006; 47: 2357-2363

[19] Lang RM, Bierig M, Devereux RB et al. Recommendations for Chamber Quantification: A Report from the American Society of Echocardiography's Guidelines and Standards Committee and the Chamber Quantification Writing Group, Developed in Conjunction with the European Association of Echocardiography, a Branch of the European Society of Cardiology. Journal of the American Society of Echocardiography 2005; 18: 1440-1463

[20] Nagueh SF, Appleton CP, Gillebert TC et al. Recommendations for the Evaluation of Left Ventricular Diastolic Function by Echocardiography. Journal of the American Society of Echocardiography 2009; 22: 107-133
[21] Wu V, Chyou JY, Chung S et al. Evaluation of diastolic function by threedimensional volume tracking of the mitral annulus with cardiovascular magnetic resonance: comparison with tissue Doppler imaging. Journal of Cardiovascular Magnetic Resonance 2014; 16: 71

[22] Schoennagel B, Fischer R, Grosse R et al. Diastolische Dysfunktion als frühes Symptom einer Herz-Eisenüberladung mittels MRT. RöFo Fortschritte auf dem Gebiet der Röntgenstrahlen und der bildgebenden Verfahren 2015; 187

[23] Zeidan Z, Erbel R, Barkhausen J et al. Analysis of global systolic and diastolic left ventricular performance using volume-time curves by real-time three-dimensional echocardiography. Journal of the American Society of Echocardiography 2003; 16: 29-37

[24] Youden W]. Index for rating diagnostic tests. Cancer 1949; 3: 32-35

[25] Kawaji K, Codella N, Prince MR et al. Automated Segmentation of Routine Clinical Cardiac Magnetic Resonance Imaging for Assessment of Left Ventricular Diastolic Dysfunction. Circulation: Cardiovascular Imaging 2009; 2: 476-484

[26] Duarte R, Fernandez-Perez G, Bettencourt N et al. Assessment of left ventricular diastolic function with cardiovascular MRI: what radiologists should know. Diagnostic and Interventional Radiology (Ankara, Turkey) 2012; 18: 446-453

[27] AlJaroudi WA, Thomas JD, Rodriguez LL et al. Prognostic Value of Diastolic Dysfunction. Cardiology in Review 2014; 22: 79-90

[28] Wan SH, Vogel MW, Chen HH. Pre-Clinical Diastolic Dysfunction. Journal of the American College of Cardiology 2014; 63: 407-416

[29] Krishnamurthy R, Pednekar A, Cheong B et al. High temporal resolution SSFP cine MRI for estimation of left ventricular diastolic parameters. Journal of Magnetic Resonance Imaging 2010; 31: 872-880

[30] Theisen D, Sandner TA, Bauner K et al. Unsupervised Fully Automated Inline Analysis of Global Left Ventricular Function in CINE MR Imaging. Investigative Radiology 2009; 44: 463-468

[31] Nassenstein K, de Greiff A, Hunold P. MR Evaluation of Left Ventricular Volumes and Function: Threshold-Based 3D Segmentation Versus ShortAxis Planimetry. Investigative Radiology 2009; 44: 635-640

[32] Shahzad R, Tao Q, Dzyubachyk O et al. Fully-automatic left ventricular segmentation from long-axis cardiac cine MR scans. Medical Image Analysis 2017; 39: 44-55

[33] Moss AJ, Zareba W, Hall W et al. Prophylactic implantation of a defibrillator in patients with myocardial infarction and reduced ejection fraction. The New England Journal of Medicine 2002; 346: 877-883

[34] Chamsi-Pasha M, Zhan Y, Debs D et al. CMR in the Evaluation of Diastolic Dysfunction and Phenotyping of HFpEF: Current Role and Future Perspectives. JACC Cardiovascular Imaging 2019 [ePub ahead of print]

[35] Huttin O, Petit MA, Bozec E et al. Assessment of Left Ventricular Ejection Fraction Calculation on Long-axis Views From Cardiac Magnetic Resonance Imaging in Patients With Acute Myocardial Infarction. Medicine 2015; 94: e1856 